\title{
O CONSÓRCIO DA CIÊNCIA E DA ARTE ENQUANTO PROJETO ESTÉTICO NORTEADOR D'OS SERTÕES, DE EUCLIDES DA CUNHA
}

Léa Costa Santana Dias ${ }^{1}$

\begin{abstract}
Resumo: Neste artigo, parte-se da própria concepção euclidiana do consórcio entre ciência e arte e se constrói um diálogo entre ambas, entendendo-as como partes indissociáveis de um mesmo discurso, que se interpenetram durante toda a narrativa, dando a Euclides a oportunidade de se constituir como aquilo que ele acreditava ser o escritor do futuro.

Palavras-Chave: Euclides da Cunha, Os sertões, Canudos, Ciência, Arte.
\end{abstract}

\begin{abstract}
In this article, is built a dialogue between science and art, starting from own Euclides' conception about the consortium among both. These are understood as inseparable parts of a same speech, that influence each other along the whole narrative, giving Euclides the opportunity to constitute himself, as he believed to be, the writer of the future.

Key Words: Euclides da Cunha, Os sertões, Canudos, Science, Art.
\end{abstract}

Em Os sertões, de Euclides da Cunha, os eventos da guerra de Canudos foram representados através de um estilo peculiar, marcado pela interinfluência entre caracteres discursivos próprios de textos literários e científicos. Desde a publicação do livro em dezembro de 1902, esse modo de narrar tem sido tema de discussões entre pesquisadores de diferentes áreas do saber.

Num texto publicado no Correio da Manhã em fevereiro de 1903, M oreira Guimarães, ex-colega de Euclides na Escola M ilitar, declarou ser Os sertões "mais produto do poeta e do artista que do observador e do filósofo" (GUIMARÃES, 2003, p. 87). Sentindo um certo desconforto em lidar com a ciência e a arte num só texto, criticou:

Por igual não se encontram nesse livro as virtudes da imaginação e os atributos da reflexão. Porque nem sempre, lado a lado, marcham, pelas páginas emocionantes dessa encantadora obra, o delicado cultor da palavra e o destemido pensador brasileiro (Idem, p. 87).

Num texto publicado em 31 de janeiro de 1903 na Revista do Centro de Ciências, Letras e Artes de Campinas, o botânico José de Campos Novaes adotou postura análoga, acusando Euclides de ter sido "algum tanto injusto no aquilatar 0 valor intrínseco dos trabalhos dos especialistas, que amam o detaIhe exato, congruente e conclusivo" (NOVAES, 2003, p. 112-3). Também teceu

1 Professora de Literatura Brasileira da Universidade do Estado da Bahia - UNEB (Departamento de Ciências Humanas e Tecnologias - Campus XXII - Euclides da Cunha). Mestra em Literatura e Diversidade Cultural pela Universidade Estadual de Feira de Santana - UEFS; endereço eletrônico: leasantana@ibest.com.br. 
críticas àquilo que considerava um estilo de "ares rebarbativos, muito diverso do estilo claro, preciso e técnico" (Idem, p. 114), indispensável aos textos científicos.

Cinqüenta anos depois da publicação de Os sertões, ao considerar o valor artístico do texto, o crítico Afrânio Coutinho aproximou-se do posicionamento assumido por Moreira Guimarães e José de Campos Novaes. Mas, ao contrário destes, elogiou esta particularidade, entendendo o livro como "uma obra de ficção, uma narrativa heróica, uma epopéia em prosa, da família de A guerra e a paz (sic), da Canção de Rolando e cujo antepassado mais ilustre é a llíada" (COUTINHO, 1995, p. 61).

Quase cem anos depois de Os sertões, o teórico Luiz Costa Lima rejeitou o caráter ficcional de Os sertões, defendido por Afrânio Coutinho, destinando à ciência o lugar-centro, o lugar de tema; e à literatura, o lugar-margem, o lugar de ornato (LIM A, 1997, p. 146). Para o crítico,

o plano literário é aceito por Euclides apenas ali onde é passível de ilustrar ou figurar mais expressivamente verdades cientificamente estabelecidas. 0 plano literário se confunde com as bordas da narrativa, formando a margem ornada, 0 ornamento aformoseador (Idem, p. 205).

Visto a partir dessa perspectiva, Os sertões seria um texto de ciência, no qual o literário aparece como um "ornamento embelezador ou ressaltante de verdades cientificamente dispostas" (Idem, p. 204).

Entre esses dois posicionamentos críticos advindos dos meios literários, que enfatizam ora a ciência (Luiz Costa Lima), ora a arte (Afrânio Coutinho), está a maior parte dos pesquisadores, que preferem classificar Os sertões como um texto de múltiplas inserções. Dentre eles, destacam-se Leopoldo Bernucci, Valentim Facioli, Walnice Nogueira Galvão, José Carlos Barreto de Santana, Roberto Ventura, José Veríssimo e Berthold Zilly.

José Veríssimo foi um dos primeiros estudiosos a considerar a hibridez discursiva de Os sertões. Num texto publicado no Correio da Manhã em 03 de dezembro de 1902, um dia após o lançamento da obra-prima euclidiana, o crítico fez a seguinte declaração:

O livro, por tantos títulos notáveis, do Sr. Euclides da Cunha, é ao mesmo tempo o livro de um homem de ciência, um geógrafo, um geólogo, um etnógrafo; de um homem de pensamento, um filósofo, um sociólogo, um historiador; e de um homem de sentimento, um poeta, um romancista, um artista, que sabe ver e descrever, que vibra e sente tanto aos aspectos da natureza, como ao contato do homem, e estremece todo, tocado até ao fundo d'alma, comovido até às lágrimas, em face da dor humana, venha ela das condições fatais do mundo físico, as "secas" que assolam os sertões do norte brasileiro, venha da estupidez ou maldade dos homens, como a campanha de Canudos (VERíSSIM 0, 2003, p. 46). 
Apesar de ter feito essa declaração sob o impacto de uma leitura rápida e superficial, Veríssimo revelou sensibilidade para apreender o que, de fato, Euclides se propunha com Os sertões, a nível estético: estabelecer, num só texto, a confluência de discursos aparentemente opostos. No entanto, mesmo reconhecendo o talento de Euclides para o manejo das antinomias, o crítico fez uma ressalva ao livro, condenando a presença de termos técnicos, arcaísmos, expressões obsoletas ou raras, neologismos e infrações à língua e à gramática, responsáveis pela falta de simplicidade na linguagem, a que considerou um defeito "de quase todos os nossos cientistas que fazem literatura" (Idem, p. 23).

Em carta ao crítico, datada de 03 de dezembro de 1902, Euclides agradeceu o modo como Os sertões foi recebido e aproveitou a oportunidade para revelar os princípios norteadores de seu projeto de escrita. Discordando do que foi dito quanto ao emprego dos termos técnicos, assegurou que eles não trouxeram prejuízo ao texto; pelo contrário, foram recursos plenamente adequados à sua proposta, fundamentada sobretudo na idéia de que "o consórcio da ciência e da arte, sob qualquer de seus aspectos, é hoje a tendência mais elevada do pensamento humano" (CUNHA, 1997, p. 143).

Antes mesmo da escrita de Os sertões, a idéia de fazer a ciência e a arte confluírem num só texto já constituía um traço significativo do pensamento de Euclides - algo que continuou a marcar os textos posteriores, sobretudo os escritos amazônicos. Trata-se de um diálogo com autores europeus cujos trabalhos são marcados pela interinfluência entre esses dois discursos. Dentre eles, Auguste Thierry, Jules Michelet, Henry Thomas Buckle, Victor Hugo, CarIyle, Hegel, Berthelot e Spencer.

Em 08 de maio de 1892, tomando como pretexto o anúncio da publicação dos livros de poemas dos escritores Júlio César da Silva e Ezequiel Ramos Júnior, Euclides publicou em 0 Estado de São Paulo, na sessão "Dia a Dia", uma crônica na qual defendia o consórcio, argumentado que "é pela arte, de uma maneira geral, que se pode formar a mais pronta, a mais ampla e a mais segura idéia da superioridade afetiva e mental de um povo" e que

a ciência, altamente cosmopolita, define na história as épocas sucessivas de elevação humana; o seu caráter de universalidade é tal que é vulgar o fato de notáveis descobertas feitas simultaneamente em pontos diferentes: define de um modo geral o espírito humano - competindo a arte mais especial, definir o espírito das nacionalidades (CUNHA, 1995, p. 672).

Através do consórcio, objetivava-se promover a fusão entre os valores universais - representados, segundo Euclides, pela ciência - e os valores particulares, nacionais - atribuídos à arte. Para que esse ideal fosse traduzido em 
linguagem, seria necessário que houvesse um grande evento histórico capaz de motivá-lo - papel desempenhado, segundo Valentim Facioli, pela guerra de Canudos (FACIOLI, 1998, p. 35-59).

Por estar inserido no contexto das três últimas décadas do século XIX, em contato com diversas correntes filosóficas, como o Darwinismo social, 0 Determinismo de Taine, o Evolucionismo de Spencer, o Positivismo de Comte e Littré etc., era natural que Euclides fizesse uso dos modelos cientificistas do seu tempo na elaboração de sua leitura dos eventos de Canudos. Além disso, deve ser considerada a própria formação intelectual do autor, adquirida na Escola Militar. Walnice Nogueira Galvão, admitindo fortes influências dessa escola sobre a formação intelectual de Euclides e sobre a elaboração de Os sertões, enfatizou que se compararmos as áreas do conhecimento mobilizadas no livro

com o currículo da Escola quando ele era aluno, verificamos que já estava familiarizado com boa parte delas. Tinha estudado na Escola química orgânica, mineralogia, geologia, botânica, arquitetura civil e militar, construção de estradas, desenho geográfico, física experimental, topografia e desenho topográfico, ótica, astronomia, geodésia, administração militar, tática e estratégia, história militar, balística, mecânica racional, tecnologia militar e as matemáticas. Afora outras, de natureza diversa destas, como direito natural e direito público, direito militar, análise de Constituição, direito internacional aplicado às relações de guerra etc. Todas essas, e mais algumas, faziam parte de seu currículo escolar. Como matérias de currículo, não teriam sido obrigatoriamente estudadas a fundo, conforme se percebe no livro, mas é com as vistas afinadas por esses saberes que Euclides avalia Canudos e a guerra² (GALVÃO, 1994, p. 624-5).

A busca pela verdade científica era uma preocupação comum a todos os intelectuais que se ocupavam com a idéia de progresso. Conforme M aria Amélia Dantes, houve no Brasil, até meados do século XIX, uma certa valorização da ciência enquanto fator de progresso, evidente, por exemplo, nas ações da Sociedade Auxiliadora da Indústria Nacional, responsável pela criação do Instituto Histórico e Geográfico Brasileiro, em 1838 - órgão importante para o resgate da história do país, bem como do seu conhecimento territorial (Dantes, 1988, p. 268). Ao se preocupar com a difusão da ciência, o país pretendia se definir no cenário mundial como sociedade científica e moderna. E porque a ciência ocupava o centro do pensamento brasileiro, também contagiou a literatura, transformando muitos romances escritos nesse período em divulgadores de modelos científicos deterministas (SCHWARCZ, 1993, p. 32).

2 José Carlos Barreto de Santana também assinalou a importância da Escola Militar na carreira de Euclides da Cunha (SANTANA, 2001, p. 40-8). 
Sendo um intelectual da época, comprometido com o ideal de progresso, Euclides estava sujeito a apreender a ciência a partir dessa perspectiva. No entanto, ao utilizá-la em sua narração dos eventos da guerra, não se transformou num simples repetidor de fórmulas, que teriam transformado sua obra num manual científico ou num árido romance de teses científicas. Euclides 0 fez acreditando estar revestido da caracterização de "escritor do futuro" princípio retomado do discurso de posse do químico francês Berthelot, na Academia Francesa, em 1901, no qual se ressalta, segundo José Carlos Barreto de Santana, ser comum naquela Academia a recepção tanto de artistas quanto de historiadores e estudiosos das ciências naturais e exatas (SANTANA, 2001, p. 22). Inspirando-se nas deduções do químico, Euclides argumentou em defesa própria: "o escritor do futuro será forçosamente um polígrafo; e qualquer trabalho literário se distinguirá dos estritamente científicos, apenas, por uma síntese mais delicada, excluída apenas a aridez característica das análises e das experiências" (CUNHA, 1997, p. 144).

A partir das afirmações de Euclides nessa carta a Veríssimo e na crônica supracitada, escrita em 1892, pode-se deduzir que a ciência e a arte aparecem em Os sertões atendendo a um projeto estético previamente elaborado, que, ao dar forma à narrativa, transformou-se num meio sobremodo eficiente, naquele momento histórico, para a representação da realidade brasileira, metaforizada nos conflitos desencadeados em Canudos.

Como o escritor permaneceu pouco tempo no cenário da guerra (talvez, menos de três semanas) e, conseqüentemente, não presenciou muitas cenas descritas no livro, surgiram-Ihe várias lacunas no processo de escritura que tiveram que ser supridas com a imaginação (ZILLY, 2001, p. 44). Lacunas tendem a ser produzidas no contato com o real que se desconhece e são propensas a serem preenchidas com o que se supõe ver ou com aquilo que o visto possibilita uma aproximação. Nesse sentido, Os sertões se assemelha às narrativas de viagens. Nestas, conforme destacou Francisco Ferreira de Lima,

\footnotetext{
o medir, pesar e comparar são atividades básicas fundamentais, por uma razão muito simples. Trata-se de aproximar o inaproximável, de maneira que esse real estranho ganhe um contorno de credibilidade e possa ser, mercê do modelo prévio, visualmente compreendido. É o meio mais eficaz para conter o desamparo do leitor, que só sabe ver o novo pelo velho (LIM A, 1998, p. 92).
}

0 homem que viajara supondo saber o que encontraria e sobre o que teria que falar teve a visão clara e precisa dos fatos desestabilizada: Canudos não se encaixou na forma pré-estabelecida. Com isso, conforme observações de Lourival Holanda Barros, o narrador passou a ter uma visão astigmata, em que não se correspondiam duas imagens: a que havia em sua mente e a que se lhe 
apresentava perante os olhos (BARROS, 1992, p. 45-6). Havia o choque perante 0 desconhecido - uma espécie de deslumbramento diante de um outro que não se adequava às descrições divulgadas oficialmente - e a necessidade de apresentá-lo ao país a partir de novas perspectivas. Havia um novo sertão, fruto das impressões da viagem, que precisava ser revelado. E, para tal, a Euclides pareceram-Ihe insuficientes as palavras. Às lacunas provindas do contato com o novo, juntaram-se outras, surgidas da própria dificuldade de se lidar com a realidade sertaneja. Havendo, então, a impossibilidade de explicar 0 fato por meio de um discurso unilateral, o escritor recorreu à arte, utilizando "a fantasia" como um meio de insurgência "contra a gravidade da ciência" (CUNHA, 2001a, p. 138), dando a impressão de que o homem de ciências se afastava da verdade científica e se aproximava da veracidade artística, contradizendo-se, de certo modo, com o posicionamento assumido na carta a Veríssimo, na qual se dizia "convencido (sic) que a verdadeira impressão artística exige, fundamentalmente, a noção científica do caso que a desperta" (CUNHA, 1997, p. 144). "Assim, onde a ciência não podia resolver, fosse por suas condições teóricas de base, fosse por carência de pesquisas, a imaginação poética estava a postos para suprir o vazio que se apresentasse" (FACIOLI, 1998, p. 54).

Através dessa forma peculiar pela qual são tratadas as palavras e a linguagem, o "rigor incoercível da verdade" (CUNHA, 2001b, p. 784) pretendido por Euclides parece ser posto em segundo plano - 0 que dá à mímese representativa um aparente domínio textual, em "que o que passa a adquirir importância parece já não ser propriamente o que se narra mas como se narra" (BERNUCCl, 1995, p. 107). Nesse encontro entre ciência e arte, emergem as muitas antíteses e paradoxos, que compõem aquilo que Walnice Nogueira Galvão classificou como o "pensamento oximorótico" de Euclides da Cunha. Por meio dele, "vemos o autor cedendo passo a um número imenso de vozes estranhas umas às outras, emitindo uma discussão de idéias muitas vezes contraditórias". Sua predileção pelas antinomias, portanto, é um recurso que "não só orna como expressa a dificuldade real de alcançar uma síntese entre doutrinas contraditórias" (GALVÃO, 1994, p. 630). Aliás,

a síntese é impossível: a verdade do livro está em suas contradições. As idéias vão e voltam, o argumento que se expõe num dado passo é seguido de seu contrário, logo depois ou centenas de páginas adiante. Tudo isso representa, no seu movimento de vaivém, a impossibilidade da inteligência brasileira de entender 0 fenômeno e de tomar um e um só partido" (Idem, p. 631).

A ciência e a arte, assim dispostas no texto, não se alternam entre si, mas formam um só discurso, particularmente antitético e antinômico. Essa opção narrativa, segundo Valentim Facioli, é fruto da consciência de que 
a ciência era cosmopolita e a arte nacional; aquela daria conta da mobilidade constante do pensamento científico na civilização ocidental; esta captaria os aspectos mais profundamente estáveis da formação étnica da nação. Aquela era o influxo do progresso; esta podia ser até contraditória com este mas devia expressar o sentido de uma evolução que a integrasse nele. 0 fundo de suas antíteses era um sentimento dramático da distância que, no Brasil, separava uma e outra (FACIOLI, 1990, p. 166).

Ou seja, na perspectiva de Euclides, os princípios de ciência e arte estavam separados, como também estavam a Europa e o Brasil. Consorciá-los era a expressão de uma impossibilidade, ou melhor, de um projeto que só poderia ser concretizado plenamente no futuro, quando o Brasil transitasse de sua "condição pré-civilizada e 'sem história' para a condição plena de civilização" (FACIOLI, 1998, p. 37), pois ao país do presente, periférico e incivilizado, restavam apenas "o desejo de ser como o centro do processo, que coincidia com 0 progresso e a civilização, e a consciência de estar fora do lugar, ou, num outro lugar, visto este como atraso e barbárie" (FACIOLI, 1990, p. 95-6). A Euclides, vivenciador desses conflitos, cabia a tarefa de representá-los. Sendo, simultaneamente, uma testemunha ocular de alguns momentos da guerra e um intelectual "envolvido com membros da comunidade científica", que sempre se definiu "como integrante dessa comunidade" (SANTANA, 2001, p. 97), sobreveio-Ihe a angústia de "dizer aquilo que a experiência própria impunha", sem a possibilidade de prescindir "da mediação das ciências-panacéia, sob pena de nem parecer moderno e civilizado, nem incluir o futuro do Brasil no processo histórico ocidental" (FACIOLI, 1990, p. 112). No texto, a angústia é expressa por meio da inversão entre essência e aparência, pois

a experiência euclidiana real (insuficiente para se constituir como ciência enquanto processo normalizador de conhecimento universal) como não coincidia com as conclusões das ciências, e não sendo descartável, só se podia expressar mediante os recursos artísticos, porque parecia a Euclides ser mera aparência concreta que ocultava verdades mais profundas e mais genéricas. A essência dessa aparência já estava dada pela generalidade das conclusões das ciências. 0 que se vê, hoje, em perspectiva, é que a essência era tomada como mera aparência e esta que, de fato, era ideologia, ou pior, era política imperalista com a cara, invisível então, de panacéia, passava por essência. Esse jogo perverso baraIhava a identidade do país e de seu sujeito cognoscente no interior dele. Era a história de um país e de um homem que precisavam ser outra coisa para se reconhecerem a si mesmos mutuamente (Idem, p. 112-3, grifos do autor).

Tanto a ciência (expressão do mundo civilizado) quanto as impressões advindas do contato com o outro (responsáveis por uma revisão de valores e 
por uma relação antitética com a ideologia republicana ${ }^{3}$ ) eram conflituosas e precisavam conviver juntas, ainda que isso só fosse possível com a inversão de seus valores. A marca de Os sertões, portanto, teria que ser a dialética - atuante na mutualidade de influxos entre a ciência e a arte, que, por serem facetas inseparáveis de um mesmo discurso, não permitiam que houvesse momentos em que uma predominasse sobre a outra. Por isso, a dissociação que alguns críticos costumam fazer entre elas mutila a escrita,

justamente porque a reorganiza numa forma lógico-racional que não é a dela. Ou seja, priva-a de sua psicologia profunda, recobrindo-a de uma projeção repressiva, espécie de necessidade racionalizadora que a tornaria domável, ou neutralizada o suficiente para se enquadrar em expectativas prévias (Idem, p. 138).

Durante todo o discurso, o autor tratou a ciência e a arte como partes indissociáveis e quase indistintas de um mesmo todo, cujas vozes muitas vezes dissonantes só se fizeram representáveis porque regidas por uma lógica própria. A essa, o critico Valentim Facioli apresentou-a como delírio, que teria seu "momento de verdade, particular e universal", que não rejeita a ciência disponível, pois estaria engendrado no "encontro desta com o olhar apaixonado (mas também colonizador) do escritor" perante o "sertão desconhecido e rebelde" (Facioli, 1998, p. 55-6).

Regido por essa força delirante, Euclides fez uma construção inusitada logo no primeiro parágrafo de Os sertões:

O planalto central do Brasil desce, nos litorais do Sul, em escarpas inteiriças, altas e abruptas. Assoberba os mares; e desata-se em chapadões nivelados pelos visos das cordilheiras marítimas, distendidas do Rio Grande a Minas. Mas ao derivar para terras setentrionais diminui gradualmente de altitude, ao mesmo tempo que descamba para a costa oriental em andares, ou repetidos socalcos, que 0 despem da primitiva grandeza afastando-o consideravelmente para 0 interior (CUNHA, 2001a, p. 71).

Segundo José Carlos Barreto de Santana, nessa descrição, o planalto brasileiro foi confundido com o planalto central, cujos limites não podiam ser definidos com precisão, mas certamente não se estenderiam do Rio Grande do Sul até M inas Gerais, nem chegariam até o Atlântico (SANTANA, 2001, p. 105).

3 Ao longo da vida, Euclides deu demonstrações claras de confiança no ideal republicano. No entanto, diante do modelo instaurado no Brasil, foram muitas suas decepções. É o que se percebe, por exemplo, numa carta ao pai, Manuel Rodrigues Pimenta da Cunha, escrita em 14 de junho de 1890: "Imagine o senhor que o Benjamim, o meu antigo ídolo, o homem pelo qual era capaz de sacrificar-me, sem titubear, e sem raciocinar, perdeu a auréola, desceu à vulgaridade de um político qualquer, acessível ao filhotismo, sem orientação, sem atitude, sem valor e desmoralizado - justamente desmoralizado" (CUNHA, 1997, p. 30).

A Cor das Letras - UEFS, n. 10, 2009 
Para chegar a essas conclusões, o historiador se utilizou das pesquisas de Aroldo de Azevedo e de outros estudiosos, dentre eles, Luís Cruls ${ }^{4}$ e Orville Derby. Segundo Derby, o planalto brasileiro estava dividido em duas partes: uma, a cadeia central ou goiana, ocupando parte do sul de Goiás e parte de Minas a oeste do rio São Francisco; a outra, a cadeia oriental ou marítima, acompanhando a costa do Atlântico, indo das proximidades do cabo de S. Roque até praticamente os limites meridionais do país e os das bacias do Paraná, Amazonas, São Francisco e Parnaíba (apud SANTANA, 2001, p. 105). Segundo Cruls, 0 planalto central, mencionado pela Constituição brasileira, possuía limites mais restritos que os propostos por Derby: abarcava a região mais central do planalto brasileiro. Sendo assim, a "única parte do planalto brasileiro que mereceria a denominação de central seria a que se achava nas proximidades dos Pirineus, no estado de Goiás" (Apud: SANTANA, 2001, p. 106).

José Carlos Barreto de Santana, analisando a denominação dada por Euclides ao planalto brasileiro (cientificamente, um erro geográfico), destacou que como o escritor conhecia trabalhos que abordavam aspectos relacionados à classificação deste planalto ${ }^{5}$, dificilmente teria cometido tal equívoco e se, por algum descuido, o tivesse cometido, é provável que o teria corrigido posteriormente, já que o desvelo dispensado às edições de Os sertões é um traço característico de sua personalidade ${ }^{6}$ (SANTANA, 2001, p. 106-8). Segundo 0

4 Numa carta de Euclides a Luís Cruls, escrita em 20 de fevereiro de 1903, fica evidente que ambos trocavam correspondências entre si (CUNHA, 1997, p 149). Cruls, professor de Astronomia na Escola Militar durante o período em que Euclides era aluno, foi convidado pelo governo republicano para chefiar a Comissão Exploradora do Planalto Central do Brasil, "encarregado de, em obediência à Constituição, demarcar a área que deveria ser reservada ao futuro Distrito Federal". 0 convite se deu em 1892, época em que era diretor do Observatório Nacional do Rio de Janeiro. 0 geólogo da Comissão era Eugênio Hussak, cujo relatório sobre a geologia do planalto central ocupou quatro páginas e meia de uma caderneta de anotações de Euclides (SANTANA, 2001, p. 106).

5 Aires de Casal, Humboldt e Derby - autores cujos trabalhos versam sobre problemas de classificação do planalto brasileiro - foram citados em Os sertões. Os livros de Wappaeus e de José Manuel de Macedo, que tratam do mesmo tema, fazem parte da relação dos livros da biblioteca de Euclides da Cunha, elaborada a partir do inventário realizado por ocasião de sua morte (SANTANA, 2001, p. 105-6).

6 Em dezembro de 1901, Os sertões foi encaminhado à Livraria Laemmert para publicação. Embora relutante, a livraria se encarregou de publicar o livro (RABELLO, 1983, p. 161). Em janeiro de 1902, Euclides recebeu as primeiras provas, dedicando-se, nos meses subseqüentes, às constantes revisões, emendas, supressões, acréscimos e correções (BERNUCCI, 2001, p. 58). Segundo Sylvio Rabello, na tipografia que imprimira a 1ạ edição do livro, o escritor pôs-se a corrigir, em cerca de mil exemplares, os erros tipográficos mais graves, utilizando nanquim e ponta de canivete. Foram oitenta emendas em cada exemplar. Oitenta mil ao todo (RABELLO, 1983, p. 165). A hipótese de que algum leitor mais exigente pudesse corrigir seu 
pesquisador, Euclides, conhecendo autores que tratavam de questões do planalto brasileiro, e citando-os como fonte, e, apesar disso, apresentando como central o planalto brasileiro, o fez porque era sua intenção fundar, por meio do discurso, uma geografia e uma paisagem específicas (Idem, p. 108-9).

Em outros momentos da narrativa, ocorrem construções semelhantes. Como exemplo, faça-se remissão ao fato de Euclides ter admitido a existência de um mar cretáceo extinto na região de Monte Santo - hipótese que deveria ter sido inviabilizada pelos estudos de Hartt e Derby, aos quais teve acesso. 0 caso, mencionado por José Carlos Barreto de Santana, ilustra a maneira como Euclides construiu a narrativa, dialogando com dados fornecidos pela ciência, selecionando informações que melhor servissem para validar cientificamente suas idéias, ainda que as mesmas fontes fossem contraditórias às suas convicções (Idem, p. 113). O historiador, destacando o contato de Euclides com os autores citados, atribuiu a escolha euclidiana à "finalidade específica de validar, pelo ponto de vista da ciência, uma 'profecia retrospectiva' que se diferenciaria da profecia de um sertão que um dia seria praia, apenas pelo sentido da seta do tempo" (Idem, p. 114). Este é o modo pelo qual Euclides teria tornado possível um paralelo entre a ciência e as supostas palavras de Conselheiro, transcritas de um texto encontrado em Belo Monte: "Em 1894 ha de vir rebanhos mil correndo do centro da Praia para o certão; então o certão virará Praia e a Praia virará certão" (Cunha, 2001a, p. 277).

Em Os sertões, aparecem apenas algumas partes deste documento, que está transcrito, na íntegra, na Caderneta de campo (CUNHA, 1975, p. 74-5). Marco Villa, utilizando a fonte de autoria euclidiana, questionou a autenticida-

livro, página por página, linha por linha, deixava-o apavorado. Por isso, dedicou vários dias de sua vida "à tarefa de emendar com a maior vigilância tudo o que lhe parecia uma impropriedade, uma obscuridade ou um defeito nas suas páginas" (Idem, p. 181). Roberto Ventura, seu último biógrafo, confirmou esse fato, apontando um número menor de correções: aproximadamente 37 - 12 acréscimos e 25 supressões - em cerca de 1200 exemplares, perfazendo 0 total de pouco mais de 44 mil emendas (VENTURA, 2002, p. 41). Seu trabalho de revisão parecia interminável: emendou para a 2ª edição, publicada em 1903; emendou para a 3ª , publicada em 1905; e, finalmente, emendou para a 4ạ, publicada em 1911, que, entretanto, reproduzia fielmente a 3 a - 0 que fez com que sua última vontade só fosse trazida a público em 1914, com a 5a edição, elaborada a partir do exemplar da 3a edição, cuidadosamente anotado pelo autor. Apesar de conter um número excessivo de emendas - 1500, segundo Sylvio Rabello (1983, p. 186); 2600, segundo Walnice Nogueira Galvão, a partir de pesquisas no apócrifo de Os sertões, transcrito do autógrafo de Euclides por Fernando Nery (GALVÃO, 1981, p. 97) -, esta edição certamente não seria a definitiva. Em sua última entrevista, concedida a Viriato Correia, publicada em 15 de agosto de 1909, o dia do assassinato, Euclides confessou: "Hei de consertar isto por toda a vida. Até já nem abro Os sertões porque fico atormentado, a encontrar imperfeições a cada passo" (CUNHA, 1995a, p. 520).

A Cor das Letras - UEFS, n. 10, 2009 
de do documento supracitado, argumentando que por ser datado de 24 de janeiro de 1890, não poderia ter sido escrito em Belo Monte, criada em junho de 1893. Para o historiador, é estranho e contraditório o fato de o documento se constituir uma profecia sobre o passado, pois, datado de 1890, começou a vaticinar acontecimentos desde 1822 (VILLA, 1999, p. 232-3). E se, de fato, este documento for apócrifo, como muitos outros que foram publicados na época e atribuídos aos conselheiristas, a sua utilização em Os sertões parece não se tratar de um simples descuido do autor. Considerando-se o rigor metodológico de Euclides da Cunha, é provável que sua opção narrativa tenha sido algo consciente e com objetivos específicos. 0 sertão, castigado pela seca, ao ser transformado em praia, estaria em maior uniformidade com a idéia de sertão paraíso que aparece no livro (CUNHA, 2001a, p. 130). Visto como praia, seria um ambiente agraciado com a abundância das águas e, em conseqüência, poderia ser descrito como a "Canaã sagrada" (Idem, p. 295), onde "nem é preciso trabalhar, [...] a terra da promissão, onde corre um rio de leite e são de cuscuz de milho as barrancas" (Idem, p. 308). De um espaço que um dia teria essas características, somente após se esgotarem as mínimas possibilidades de sobrevivência é que, segundo Euclides, o sertanejo sairia choroso, num "êxodo penosíssimo para a costa, para as serras distantes, para quaisquer lugares onde o não mate o elemento primordial da vida" (Idem, p. 237). 0 sertão praia é o sonho do sertanejo que permanece na terra apesar da fome, da seca, da miséria e da marginalização social. É o sonho do sertanejo migrante, que aguarda ansioso a chegada das chuvas a fim de retornar feliz, "esquecido de infortúnios, buscando as mesmas horas passageiras da ventura perdidiça e instável, os mesmos dias longos de transes e provações demorados" (Idem, p. 237).

Ao adornar a cidadela de Canudos com tais simbologias, Euclides tornoua passível de ser liderada por D. Sebastião, rei português desaparecido em Alcácer-Quibir, na África, em 1578. Apesar de nos relatos dos sobreviventes da guerra não existir qualquer menção ao sebastianismo (VILLA, 1999, p. 234; GALVÃO, 2001, p. 108), há remissão ao rei português nos folhetos proféticos encontrados no arraial e transcritos por diversos autores (GALVÃO, 2001, p. 108). No final do século $X I X$, usou-se largamente o termo sebastianismo para nomear todos os que defendiam a restauração monárquica (VILLA, 1999, p. 234). Aliás, nem mesmo era preciso haver qualquer intenção monarquista nas ações dos que se opunham ao regime em vigor para que fossem considerados sebastianistas pelos representantes da elite brasileira. Euclides, como pensador inserido nesse contexto, não ficou imune a essa tendência e aplicou o termo aos habitantes de Canudos, citando, tanto em Os sertões (CUNHA, 2001a, 
p. 319-20) quanto na Caderneta de campo (CUNHA, 1975, p. 59-61), quadras da poesia popular que sugeriam o paralelo. Vale ressaltar, no entanto, que os moradores de Canudos não eram defensores da volta do regime monarquista, tampouco os sebastianistas portugueses eram anti-republicanos, até porque, em Portugal, a República só viria anos depois. A analogia entre eles só se tornou possível mediante um tratamento ideológico e estético. Ao sugerir o paralelo, Euclides aproximou o movimento de Canudos de outros movimentos brasileiros, como, por exemplo, do episódio da Pedra Bonita ${ }^{7}$, ocorrido em Pernambuco, entre os anos de 1836 a 1838, "onde D. Sebastião era a presença tutelar, conjurada à custa de sacrifícios humanos"8 (GALVÃO, 2001, p. 107). Ao mesmo tempo, Euclides reforçou a metáfora da Vendéia, com sua conotação anti-monarquista, embora tal imagem tenha sofrido ao longo do texto um abalo de credibilidade, como a própria idealização euclidiana da República. 0 sebastianismo português e a Vendéia francesa, apesar de inaplicáveis à realidade sertaneja, possibilitavam o estabelecimento de uma ponte entre o conhecido e 0 desconhecido. Foram estratégias utilizadas por Euclides para transpor, via linguagem, 0 abismo existente entre 0 interior bárbaro e o litoral europeizado, entre o Brasil, que almejava civilizar-se, e a Europa, civilizada e moderna.

Outro fato representado em Os sertões de forma altamente transgressora à veracidade dos fatos é o momento em que o frei João Evangelista de Monte-Marciano retirou-se do arraial, após fracassada tentativa de persuadir os sertanejos a desertarem de Canudos. Ao partir, o frei possivelmente disse apenas a seguinte frase: "Se vocês não se dispersarem, então um dia vocês podem ser castigados pelo último juízo" (apud ZILLY, 2001, p. 45). No entanto, foi descrito como se tivesse agido de modo semelhante aos apóstolos quando mal recebidos nas cidades que visitavam. Segundo Euclides, ao sair do arraial, o missionário "sacudiu o pó das sandálias", "apelando para o veredictum tremendo da Justiça Divina..." (CUNHA, 2001a, p. 327). Apesar de ter tido acesso ao Relatório do frei, Euclides ignorou certas informações, narrando o espetáculo da partida da seguinte maneira:

\footnotetext{
E abalou, furtando-se a seguro pelos becos, acompanhado dos dois sócios de reveses...

Galga a estrada coleante, entre os declives da Favela.

Atinge 0 alto da montanha. Pára um momento...
}

7 Este episódio é citado em Os sertões (CUNHA, 2001a, p. 243-4).

8

Alguns anos após a guerra de Canudos, entre os anos de 1912 a 1916, ocorreu em Santa Catarina a sublevação do Contestado, "de sebastianismo não só evidente como explícito na boca dos insurrectos". Nessa espécie de Guerra Santa, São Sebastião, amalgamado a D. Sebastião, era o santo padroeiro, invocado "no intróito solene dos documentos, ao lado da Santíssima Trindade" (GALVÃO, 2001, p. 107). 
Considera pela última vez o povoado, embaixo...

É invadido de súbita onda de tristeza. Equipara-se ao "Divino Mestre diante de Jerusalém".

Mas amaldiçoou... (Idem, p. 327).

Diante do procedimento narrativo adotado, percebe-se que Euclides preferiu ao aproveitamento realista da fonte a sua ficcionalização, certamente por possibilitar maior expressividade ao discurso. A frase "M as amaldiçoou..." é a última da segunda parte do livro e, portanto, a última antes do começo de "A luta". A partir dela, "o leitor fica na expectativa da realização ou não dessa maldição. Pura técnica de suspense", conforme destacou Berthold Zilly (2001, p. 45). Pensando-se a partir da "Nota preliminar", pode-se dizer que essa maldição foi impulsionada pela "força motriz da História", que, por sua vez, implicou o "esmagamento inevitável das raças fracas pelas raças fortes" (CUNHA, 2001c, p. 66). Este, no entanto, processou-se de forma truncada em Canudos. Afinal, a civilização do litoral foi mal sucedida em seu propósito de "trazer para o nosso tempo e incorporar à nossa existência aqueles rudes compatriotas retardatários" (CUNHA, 2001a, p. 682). E como não foi dada aos sertanejos a oportunidade de serem incorporados à civilização, o que houve em Canudos, na interpretação de Euclides, foi "um crime", "um refluxo para o passado" (CUNHA, 2001c, p. 67). Disso advém a crítica à ciência, que, intimada a dizer as últimas palavras nas linhas finais do livro, tornou-se frágil e emudecida: "É que ainda não existe um Maudsley ${ }^{9}$ para as loucuras e os crimes das nacionalidades" (CUNHA, 2001a, p. 781).

\section{REFERÊNCIAS}

BARROS, Lourival Holanda. Canudos - fato e fábula (uma leitura d'Os sertões de Euclides da Cunha). 129f. 1992. Tese de Doutorado - Faculdade de Filosofia, Letras e Ciências Humanas / Universidade de São Paulo, São Paulo.

BERNUCCl, Leopoldo M. A imitação dos sentidos; prógonos, contemporâneos e epígonos de Euclides da Cunha. São Paulo: EDUSP, 1995.

BERNUCCI, Leopoldo M. Cronologia. In: CUNHA, Euclides da. Os sertões. 2. ed. São Paulo: Ateliê Editorial, Imprensa Oficial do Estado, Arquivo do Estado, 2001, p. 51-61. Edição, prefácio, cronologia, notas e índices Leopoldo M. Bernucci.

COUTINHO, Afrânio. Os sertões, obra de ficção. In: CUNHA, Euclides da. Obra completa, vol. 2. Rio de Janeiro: Nova Aguilar, 1995, p. 61-6.

CUNHA, Euclides da. Caderneta de campo. São Paulo: Cultrix; Brasília: INL, 1975.

9 O inglês Henry Maudsley (1835-1918) foi um médico alienista, professor de Medicina Legal em Londres. Dentre as várias obras que escreveu, destaca-se 0 crime e a loucura. 
CUNHA, Euclides da. Dia a Dia. Crônica. In: Id. Obra completa, vol. 1. Rio de Janeiro: Nova Aguilar, 1995, p. 645-91.

CUNHA, Euclides da. A última entrevista. Outros contrastes e confrontos. In: Id. Obra completa, vol. 1. Rio de Janeiro: Nova Aguilar, 1995a, p. 518-23.

CUNHA, Euclides da. Correspondência (1890-1909). In: GALVÃO, Walnice Nogueira, GALOTTI, Oswaldo. (Org.). Correspondência de Euclides da Cunha. São Paulo: EDUSP, 1997.

CUNHA, Euclides da. Os sertões. 2. ed. São Paulo: Ateliê Editorial, Imprensa Oficial do Estado, Arquivo do Estado, 2001a. Edição, prefácio, cronologia, notas e índices Leopoldo M. Bernucci.

CUNHA, Euclides da. Notas à segunda edição. In: Idem. Os sertões. 2. ed. São Paulo: Ateliê Editorial, Imprensa Oficial do Estado, Arquivo do Estado, 2001b, p. 783-92. Edição, prefácio, cronologia, notas e índices Leopoldo M. Bernucci.

CUNHA, Euclides da. Nota preliminar. In: Id. Os sertões. 2. ed., São Paulo: Ateliê Editorial, Imprensa Oficial do Estado, Arquivo do Estado, 2001c, p. 65-7. Edição, prefácio, cronologia, notas e índices Leopoldo M. Bernucci.

DANTES, M aria Amélia M. Fases da implantação da ciência no Brasil. Quipu; Revista Latinoamericana de Historia de las Ciencias y la tecnologia. Mexico, Facultad de Filosofia, v. 5, n. 2, p. 26575, maio-ago. 1998.

DIAS, Léa Costa Santana. 0 (des)tecer de enredos: uma leitura d'Os sertões, de Euclides da Cunha. 134f. 2003. Dissertação (Mestrado em Literatura e Diversidade Cultural) - Programa de Pós-Graduação em Literatura e Diversidade Cultural, Universidade Estadual de Feira de Santana, Feira de Santana.

FACIOLI, Valentim A. Euclides da Cunha: a gênese da forma. 172f. 1990. Tese de Doutoramento Faculdade de Filosofia, Letras e Ciências Humanas da Universidade de São Paulo, São Paulo.

FACIOLI, Valentim A. Euclides da Cunha: consórcio de ciência e arte (Canudos: o sertão em delírio). In: BRAIT, Beth. (Org.). 0 sertão e os sertões. São Paulo: Arte \& Ciência, 1998, p. 35-59.

GALVÃO, Walnice Nogueira. Ciclo de Os sertões. In: Id. Gatos de outro saco; ensaios críticos. São Paulo: Brasiliense, 1981, p. 61-110.

GALVÃO, Walnice Nogueira. Euclides da Cunha. In: PIZARRO, Ana. (Org.). América Latina: palavra, literatura e cultura. São Paulo: M emorial; Campinas: UNICAMP, v. 2, 1994, p. 615-33.

GALVÃo, Walnice Nogueira. 0 império do Belo Monte; vida e morte de Canudos. São Paulo: Fundação Perseu Abramo, 2001.

GUIM ARÃES, Moreira. O livro de Euclides da Cunha. In: FACIOLI, Valentim, NASCIMENTO, José Leonardo do. (Org.). Juízos críticos: Os sertões e os olhares de sua época. São Paulo: Nankin Editorial, Unesp, 2003, p. 87-101.

LIMA, Francisco Ferreira de. 0 outro livro das maravilhas; a peregrinação de Fernão Mendes Pinto. Rio de Janeiro: Relume Dumará; Salvador, Bahia: Fundação Cultural do Estado da Bahia, 1998.

LIM A, Luiz Costa. Terra ignota; a construção de Os sertões. Rio de Janeiro: Civ. Brasileira, 1997 NOVAES, José de Campos. Os sertões (Campanha de Canudos) por Euclydes da Cunha. In: FACIOLI, Valentim, NASCIM ENTO, José Leonardo do. (Org.). Juízos críticos: Os sertões e os olhares de sua época. São Paulo: Nankin Editorial, Unesp, 2003, p. 112-22. 
RABELLO Sylvio. Euclides da Cunha. 3. ed., Rio de Janeiro: Civilização Brasileira; Brasília: INL, 1983. Coleção Vera Cruz.

SANTANA, José Carlos Barreto de. Ciência e arte: Euclides da Cunha e as ciências naturais. São Paulo: HUCITEC; Feira de Santana: Universidade Estadual de Feira de Santana, 2001.

SCHWARCZ, Ĺlia Katri Moritz. Entre homens de sciencia. 0 espetáculo das raças; cientistas, instituições e questões raciais no Brasil - 1870-1930. São Paulo: Cia. das Letras, 1993, p. 23-42.

VENTURA, Roberto. Do mar se fez o sertão: Euclides da Cunha e Canudos. Revista Canudos. Salvador, UNEB, ano 7, n. 6/7, p. 39-69, jan./ dez, 2002.

VERÍSSIM O, José. Uma história dos sertões e da Campanha de Canudos (Os sertões, campanha de Canudos por Euclides da Cunha, Laemmert \& C., editores). In: FACIOLI, Valentim, NASCIM ENTO, José Leonardo do. (Org.). Juízos críticos: Os sertões e os olhares de sua época. São Paulo: Nankin Editorial, Unesp, 2003, p. 46-54.

VILLA, Marco Antonio. Canudos - o povo da terra. São Paulo: Ática, 1999, 280p.

ZILLY, Berthold. A guerra de Canudos e 0 imaginário da sociedade sertaneja em Os sertões, de Euclides da Cunha. In: CHIAPPINI, Lígia, AGUIAR, Flávio Wolf de. (Org.). Literatura e História na América Latina; Seminário Internacional, 09 a 13 de setembro de 1991. 2. ed., São Paulo: EDUSP, 2001, p. 37-47. 
